\title{
Successful Rate of Stature Estimation Using Odontometric Parameter with Carrea's Index in Mongoloid Population
}

\author{
Dina Karimah Putri ${ }^{1}$, Mieke Sylvia Margaretha Amiatun Ruth ${ }^{2}$, Toetik Koesbardiati \\ ${ }^{1}$ Staff of Dental Radiology Department, Faculty of Dental Medicine, Universitas Airlangga, ${ }^{2}$ Staff of Odontology \\ Forensic Department, Faculty of Dental Medicine, Universitas Airlangga, ${ }^{3}$ Staff of Anthropology Department, \\ Faculty of Social Sciences and Political Sciences, Universitas Airlangga, Surabaya-Indonesia
}

\begin{abstract}
Background: Stature estimation is one of the four pillars in the anthropological identification protocol. During this time, stature estimation uses long bones, but if no long bones are found, tooth dimensions begin to be examined as a tool in stature estimation.

Purpose: The aim of this study was to be able to determine the percentage of success in using tooth dimensions to estimate height in the Mongoloid population in Indonesia, using the Carrea's Index method.

Method: The study was carried out by measuring the dimensions of arch and chord, then put into the Carrea formula, the results were compared with actual height, then calculated the frequency of predictions of success and non-success, compared to gender, and quadrant side of jaw.

Results: The results of predictions of success for both women and men on both sides of the mandibular were a successful prediction of $69.6 \%$ and a non-successful prediction of $30.4 \%$. In each sex, the success rate was different for each side, without a statistically significant difference (right $p$ value 0.186 ; left $p$ value 0.713 ) using Chi-square test. The results of the Pearson Correlation Coefficient test have a positive correlation ( $p$ $<0.05$ ) indicating that there is a significant relationship between height and the results of height estimation obtained from tooth dimension measurements.
\end{abstract}

Conclusion: Based on the successful rate of the Carrea's Index method in this study shows that the Carrea's Index method can be used in the Mongoloid population in Indonesia as a tool for human identification.

Keywords: Anthropology, carrea's index, forensic identification, odontology, stature estimation.

\section{Introduction}

Indonesia is the most disaster-prone country in the world according to data compiled by the United Nations Agency (UN) in the field of the International Strategy

\section{Corresponding Author:}

\section{Dina Karimah Putri}

Jl. Prof. Dr. Moestopo No. 47

Phone Numbers: (+6231) 5030255, 5020256

Facsimile Numbers: (+6231) 5020256

e-mail: dina.karimah.p@fkg.unair.ac.id for Disaster Risk Reduction (UN-ISDR) because it is included in the five most populous countries in the world, so there are potentially many victims threatened the risk of loss of life in the event of a disaster ${ }^{1}$. In addition, geographically Indonesia is an archipelago that crosses the equator and is included in the Eurasian Circum Pacific Ring of Fire and is located at the confluence of four tectonic plates namely the Asian Continent, the Continent Australia, the Indian Ocean, and the Pacific Ocean, so that they are potentially at the same time prone to disasters such as volcanic eruptions, earthquakes, tsunamis, floods, and landslides ${ }^{2}$. Disasters can be caused by natural factors (natural disasters) and by human actions (man-made disasters), such as crime, 
terrorism, transportation accidents. These disasters are undeniably caused many victims, both alive and dead.

Every person who has died and cannot be identified or without identity must take the forensic identification stage, as stated in article 118 paragraph (1) of Law no. 36 of 2009 concerning Health, which reads "Unknown bodies must be made an effort to identify" 3 . This identification process is something important because it involves medicolegal and human rights aspects ${ }^{4}$. Identification of individuals will be easy to do if visuals can be recognized, but in cases that cause death, often the individual's body becomes difficult to recognize due to the trauma, such as being cut into pieces (mutilated), damaged by severe accidents for example in transportation accidents (Air Asia 2014, Zahro Express ship, deadly accident at Puncak 2017, Lion Air 2018), fragmented $/$ crushed $^{5}$, decayed ${ }^{6}$, burnt because of fire accident, bomb blast, or only human skeletal remains that left to identify.

Estimating body posture is an important step in reconstructive identification of skeletal remains or body remains that are difficult to recognize. In anthropology, height estimation can be obtained from various parts of the body ${ }^{7}$ and, most commonly, using long bones ${ }^{8}$. But in some cases, not all parts of human bones can be found, especially if only jaws and leftover teeth are found. So under these conditions, investigators and researchers began to pay attention to the estimation of height through the skull and tooth dimensions ${ }^{9}$. But until now, only a few studies have evaluated the possibility to estimate height through the dimensions of the tooth. The main consideration regarding the reason teeth can be used for height estimation is that no two individuals have identical teeth and there is a presumption in society that a person with high body posture has large dental dimensions and arches, as well as the nature of teeth that are resistant to changes in perimortem and post-mortem, so these characteristics make teeth have an important role in the process of individual identification ${ }^{10}$.

In an effort to examine the use of teeth to estimate height $^{11}$, researchers from outside Indonesia, have conducted several studies using a variety of method using tooth dimensions as parameters (odontometric parameters), both using permanent maxillary teeth ${ }^{5,12-15}$, permanent mandibular teeth $9,10,16,17$, as well as a combination of maxillary and mandibular permanent teeth $^{18}$, some have even examined using deciduous teeth $^{19}$. Odontometric parameters that have been used include tooth length, crown length, mesiodistal width, labiolingual/buccolingual width, and relationship to facial measurements. In studies using maxillary permanent teeth parameters, the results show that the mesio-distal width of maxillary canines has a significant correlation with height $^{12,15,20}$, however, with linear regression formula that varies depending on the population and sample. According to Yadav et al.'s research, the regression equation generated from odontometric parameters can be used as an additional approach to estimating body height if the bone extremity is not available, but only in the same specific population ${ }^{15}$. Interestingly, for mandibular permanent teeth parameters, some researchers used the same method using a formula called the Carrea's Index $\mathrm{x}^{9,10,16,17}$. Although the study was conducted in different populations, the significant results obtained are the same, namely Carrea's Index method can be used to estimate the height in their population. Carrea's Index method is a method that was discovered by Carrea in 1920 , which uses the parameters of the mandibular anterior permanent teeth by measuring two dimensions namely arch and chord ${ }^{16}$. Based on previous research using the Carrea's Index method the advantages of this method are easy and simple because the formula is already found, it can be used in normal and crowded tooth conditions, and because the measured dimensions are horizontal dimensions (mesiodistal width of teeth and dental arch), so they are not affected by changes in the vertical dimensions of teeth, for example, due to attrition, as well as due to local cultural rituals that change to condition of the tooth (for example, pangur). In addition, when observing the findings of cases in the field, the anatomical position of the mandibular anterior teeth crowns is behind the anterior maxillary teeth so that they are adequately protected from trauma and damage before and after death.

Because the Carrea's Index method is based on the previous study, the accuracy of the results is good, namely above $70 \%$ used in some populations ${ }^{9,10,16}$, so in this study, the writer wants to examine the accuracy of the estimated height using the Carrea's Index method on the Mongoloid population in Indonesia. It is hoped that later the results of this study can be an inspiration or further study to develop related method or other method in estimating body height using dental dimensions to support the process of identifying bodies in the forensic field in Indonesia in particular. 


\section{Materials and Method}

This study is an observational analytic with a crosssectional design ${ }^{21,2221}$. The subjects in this study are the Mongoloid population - the largest group found in Indonesia - who are clinical patients of the Orthodontic Residents in Orthodontic Residency Program (PPDGS), at Oral Medical Education Hospital (RSGM-P), Faculty of Dental Medicine, Airlangga University, over the past year, with the following inclusion criteria:

- The age range of patients is 21-25 years

- Complete mandibular anterior teeth

- There are no anatomical, morphological abnormalities or pathological conditions and healthy periodontal tissue.

The sampling technique uses a total sampling method. The total sample is 46 subjects with mandibular dental molds, with a sampling unit that is one side of the mandibular quadrant, so that the total number of samples was 92 samples (for the right and left quadrants). While the exclusion criteria for the sample in this study as follow:

- Not willing to be the subject of the study.

- Not getting approval from the treating dentist.

- Not from the Mongoloid population.

- Have a history of mandibular anterior restorative, crowded teeth, or diastema.

- Have a history of abnormalities related to growth, such as abnormalities in the number of teeth, tooth size and shape, tooth eruption time, and abnormalities in tooth structure ${ }^{23}$.
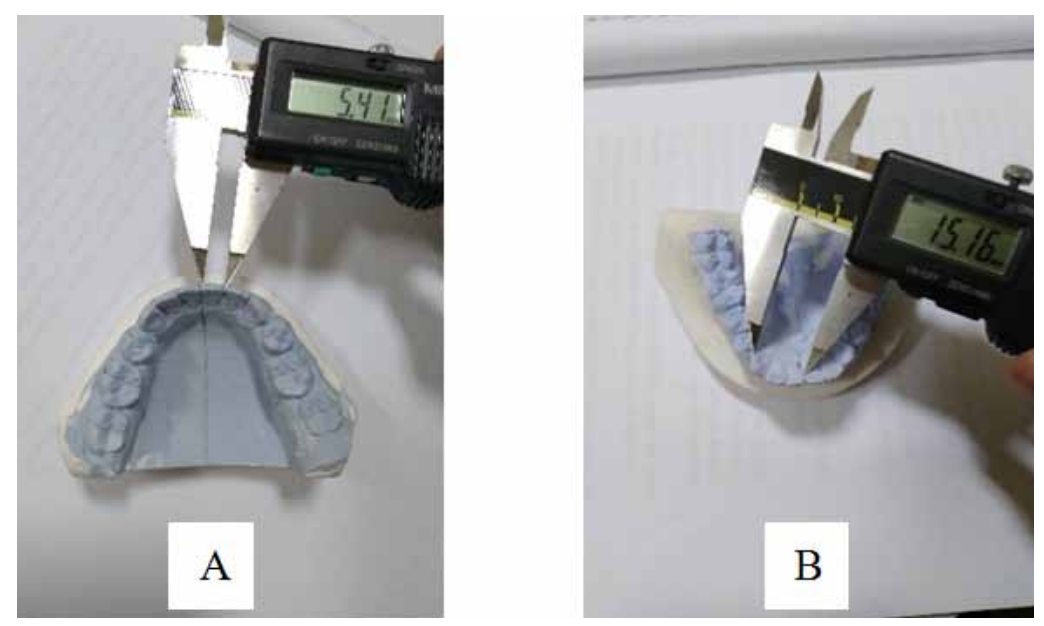

Figure 1 Arch (A) and chord (B) measurements method using digital sliding caliper with Mitutoyo Absolute Digimatic brand.
Each subject has explained the intentions and procedures in this study, and each subject fills informed consent. This study has also received Ethical approval from the Ethics Committee of the Faculty of Dental Medicine, Airlangga University. The procedure of this study as follow:

1. Actual body height (BH) measurement: The subject was measured using a One Med stature meter with the subject standing upright in a horizontal plane, barefoot, in an anatomical position according to the Frankfurt field, holding the breath, aligning the posterior surface of the heel, hips, shoulders, and nape in the vertical plane. Height is recorded in the subject's identity form. Measurements were made by one person, the author himself. For intraexaminer variability, the height measurements were repeated for 12 subjects.

2. Arch and chord measurement: Arch is the sum of mesiodistal widths of one side of the mandible anterior measured from the labial surface, while the chord is the distance between the mesial edge of the central incisors and the distal edge of the canines on the same side measured from the lingual surface. It was measured using a sliding caliper according to the Carrea's Index in the mandibular mold for each side of the mandibular quadrant, then the measurement results are entered into the Carrea formula to determine the estimated minimum and maximum height. Calculation results in millimeters are then converted to centimeters. For intra-examiner variability, the arch and chord measurements were repeated on 12 sample. 


\section{Carrea Formula:}

$\operatorname{Max} \mathrm{BH}=\underline{\operatorname{arch}(\text { in } \mathrm{mm}) \times 6 \times 3.1416 \times 100}$

2

$\operatorname{Min} \mathrm{BH}=\frac{\text { chord }(\text { in } \mathrm{mm}) \times 6 \times 3.1416 \times 100}{2}$

2

Comparison of estimated results with actual $\mathrm{BH}$ : The Max BH and Min BH values are the estimated range of the subject's height which will then be compared to the actual body height of the subject, with the following conditions:

- Successful Predicition à if the actual height measurement results are in the range between the estimated minimum height and maximum height measurements.

- Unsuccessful Predicition $\rightarrow$ if the actual height measurement results are not in the range between the measurement results of the estimated minimum height and maximum height. ${ }^{7}$ Then the frequency of successful prediction and unsuccessful predicition in both men and women, both right and left side is calculated.

Data analysis: The proportion of accuracy is compared by sex, and the jaw quadrant side uses the Chi-square test. Carrea's Index method reliability was tested with Pearson's coefficient and Kappa Index to determine intra-examiner reliability. This study uses a $95 \%$ confidence level, with a $\mathrm{p}$-value $<0.05$ considered statistically significant.

\section{Results}

In this study, according to the results of the intraexaminer test, obtained reliable results with a Kappa Index coefficient of 0.897 , which means that there is a very strong consistency (coefficient value close to 1) between the first and second height measurements in 12 subjects and arch and chord dimension measurements of 12 mandibular mold by the authors. Based on the Kappa Index test, a significant $p$ value was obtained at 0,000 using a $95 \%$ confidence interval, where a $p$ value $<0.05$, so this indicates that there was significant consistency between the first and second measurements.

Descriptive statistics of gender-related subjects consisted of 38 women $(82.6 \%)$ and 8 men $(17.4 \%)$ so that the sample was 92 (for a total of 2 sides of the mandibular quadrant with 46 samples each).

Table 1 The mean value of age, height, and estimated height (maximum and minimum).

\begin{tabular}{|c|c|c|c|c|c|c|}
\hline \multirow{2}{*}{ Mean } & \multicolumn{2}{|c|}{ Female } & \multicolumn{2}{|c|}{ Male } & \multicolumn{2}{|c|}{ Total } \\
\hline & Right & Left & Right & Left & Right & Left \\
\hline Age (years) & \multicolumn{2}{|c|}{$22 \pm 1.16$} & \multicolumn{2}{|c|}{$22 \pm 1.20$} & \multicolumn{2}{|c|}{$22 \pm 1.16$} \\
\hline Body Height (cm) & \multicolumn{2}{|c|}{$157.14 \pm 7.48$} & \multicolumn{2}{|c|}{$167.53 \pm 4.72$} & \multicolumn{2}{|c|}{$158.95 \pm 8.08$} \\
\hline Maximum Body Height (cm) & $166.39 \pm 10.28$ & $165.70 \pm 10.26$ & $169.30 \pm 11.74$ & $169.76 \pm 9.96$ & $166.90 \pm 10.46$ & $166.40 \pm 10.22$ \\
\hline Minimum Body Height $(\mathrm{cm})$ & $150.95 \pm 11.55$ & $149.40 \pm 11.61$ & $156.81 \pm 12.89$ & $158.12 \pm 10.44$ & $150.92 \pm 11.79$ & $150.92 \pm 11.79$ \\
\hline Total Estimated Height $(\mathrm{cm})$ & $158.67 \pm 10.92$ & $157.55 \pm 10.94$ & $163.06 \pm 12.32$ & $163.94 \pm 10.20$ & $159.44 \pm 11.16$ & $158.66 \pm 11.00$ \\
\hline
\end{tabular}

Based on table 1 above, the mean value of the subjects of the study, both female and male, was $22 \pm$ 1.16 years. The table also shows the comparison of the actual average height of the subjects with the estimated height obtained from the arch (maximum height) and chord (minimum height) values in each sample calculated by the Carrea's Index formula. It appears that of the 46 subjects, male subjects had higher average height and the estimated height than female subjects. Meanwhile, when viewed from the calculation of the estimated height between the sides of the mandibular quadrant, in female subjects, the estimated height results on the right side are higher than the results of the calculation of the estimated height of the left side. In contrast to male subjects, the estimated height results on the left side are higher than the results of the estimated right side height estimates. The total estimated height of the right side in female subjects $(158.67 \pm 10.92 \mathrm{~cm})$ differed by $1.53 \pm$ $3.44 \mathrm{~cm}$ from the actual height of the female subjects $(157.14 \pm 7.48 \mathrm{~cm})$, and the total estimated height the left side body in the female subject $(157.55 \pm 10.94 \mathrm{~cm})$ differed by $0.41 \pm 3.46 \mathrm{~cm}$ from the actual height of the female subject $(157.14 \pm 7.48 \mathrm{~cm})$. Meanwhile, the total estimated height of the right side in male subjects 
$(163.06 \pm 12.32 \mathrm{~cm})$ differed by $4.47 \pm 7.6 \mathrm{~cm}$ from the actual body height of male subjects $(167.53 \pm 4.32 \mathrm{~cm})$, and the total estimated left-side height in male subjects $(163.94 \pm 10.20 \mathrm{~cm})$ differed by $3.59 \pm 5.48 \mathrm{~cm}$ from the actual height of male subjects $(167.53 \pm 4.32 \mathrm{~cm})$.

Table 2 Distribution of successful and unsuccessful predictions from height estimation results by gender

and jaw quadrant side

\begin{tabular}{|c|c|c|c|c|c|c|c|c|c|c|c|c|}
\hline \multirow{3}{*}{ Gender } & \multicolumn{4}{|c|}{ Right } & \multirow{2}{*}{\multicolumn{2}{|c|}{ Total }} & \multicolumn{4}{|c|}{ Left } & \multirow{2}{*}{\multicolumn{2}{|c|}{ Total }} \\
\hline & \multicolumn{2}{|c|}{ Successful } & \multicolumn{2}{|c|}{ Unsuccessful } & & & \multicolumn{2}{|c|}{ Successful } & \multicolumn{2}{|c|}{ Unsuccessful } & & \\
\hline & $\mathbf{N}$ & $\%$ & $\mathbf{N}$ & $\%$ & $\mathbf{N}$ & $\%$ & $\mathbf{N}$ & $\%$ & $\mathbf{N}$ & $\%$ & $\mathbf{N}$ & $\%$ \\
\hline Female & 28 & 73.7 & 10 & 26.3 & 38 & 82.6 & 26 & 68.4 & 12 & 31.6 & 38 & 82.6 \\
\hline Male & 4 & 50 & 4 & 50 & 8 & 17.4 & 6 & 75 & 2 & 25 & 8 & 17.4 \\
\hline Total & 32 & 69.6 & 14 & 30.4 & 46 & 100 & 32 & 69.6 & 14 & 30.4 & 46 & 100 \\
\hline p-value & \multicolumn{4}{|c|}{0.186} & & & \multicolumn{4}{|c|}{0.713} & & \\
\hline
\end{tabular}

Table 2 below shows the distribution of successful and unsuccessful prediction results from the calculation of estimated height using the Carrea's Index method to the actual height of the study subject based on gender and the side of the mandibular quadrant using the Chisquare test. From 38 female subjects, on the right side, 28 subjects $(73.7 \%)$ showed successful predictions, while the remaining 10 subjects $(26.3 \%)$ showed unsuccessful predictions. From 8 male subjects, on the right side, the results of a balanced and successful prediction were obtained, namely, 4 subjects $(50 \%)$ had successful predictions, and 4 subjects $(50 \%)$ had unsuccessful predictions. Thus it can be seen that a higher percentage of success was found in female subjects compared to male subjects on the right side, but there was no statistically significant difference $(p=0.186)$. Overall on the right side, there were 32 samples $(69.6 \%)$ with successful predictions and 14 samples (30.4\%) with unsuccessful predictions.

There was a slight differences found on the left side, where there were fewer female subjects who had success predictions compared to the right side, namely 26 subjects $(68.4 \%)$, while 12 subjects $(31.6 \%)$ had unsuccessful predictions. In contrast, in male subjects, on the left side of the number of samples with more successful predictions than the right side, namely 6 subjects $(75 \%)$, while those who have unsuccessful predictions are 2 subjects (25\%). Thus, on the left side, it appears that male subjects have a higher percentage of success than female subjects, but there is no statistically significant difference $(p=0.713)$. Overall on the left side, the percentage of success is not different from the right side, that is, there are 32 samples $(69.6 \%)$ with predictions of success and 14 samples (30.4\%) with predictions of no success.

\section{Table 3 Correlation test results of actual height to estimated height with Carrea's Index (Pearson correlation coefficient).}

\begin{tabular}{|c|l|c|c|c|c|}
\hline \multicolumn{2}{|c|}{} & $\begin{array}{c}\text { Maximum Body } \\
\text { Height (Right) }\end{array}$ & $\begin{array}{c}\text { Minimum Body } \\
\text { Height (Left) }\end{array}$ & $\begin{array}{c}\text { Maximum Body } \\
\text { Height (Right) }\end{array}$ & $\begin{array}{c}\text { Minimum Body } \\
\text { Height (Left) }\end{array}$ \\
\hline \multirow{3}{*}{ Body Height } & Pearson correlation & $0.471^{* *}$ & $0.476^{* *}$ & $0.452^{* *}$ & $0.515^{* *}$ \\
\cline { 2 - 6 } & p-value & 0.001 & 0.001 & 0.002 & 0.000 \\
\cline { 2 - 6 } & $\mathrm{N}$ & 46 & 46 & 46 & 46 \\
\hline
\end{tabular}

\footnotetext{
** Correlation is significant at the 0.01 level (2-tailed)
} 
Table 3 above shows the results of the correlation analysis between actual height and estimated maximum and minimum height on both the right and left sides. From this table, it is known that the Pearson correlation coefficient value between the height variable and each estimated height variable is greater than zero to maximum body height of the right side is 0.471 ; to the maximum body height of the left side is 0.476 ; to the minimum body height of the right side is 0.452 , and with a minimum body height of left side is 0.515 . The Pearson correlation coefficient value which is getting closer to 1 indicates a stronger correlation, so from the four estimated height variable, the minimum body height of the left side coefficient is closest to 1 which means that the variable has the strongest correlation to the height variable compared to the another estimated height variable.

Table 4 Correlation test results from actual height to estimated height with a Carrea's Index (Pearson correlation coefficient) on female subjects

\begin{tabular}{|c|l|c|c|c|c|}
\hline \multicolumn{7}{|c|}{ Correlations $^{\mathbf{a}}$} \\
\hline \multirow{2}{*}{} & $\begin{array}{c}\text { Maximum Body } \\
\text { Height (Right) }\end{array}$ & $\begin{array}{c}\text { Minimum Body } \\
\text { Height (Left) }\end{array}$ & $\begin{array}{c}\text { Maximum Body } \\
\text { Height (Right) }\end{array}$ & $\begin{array}{c}\text { Minimum Body } \\
\text { Height (Left) }\end{array}$ \\
\hline \multirow{3}{*}{ Body Height } & Pearson correlation & $0.455^{* *}$ & $0.425^{* *}$ & $0.409^{*}$ & $0.430^{* *}$ \\
\cline { 2 - 6 } & Sig. (2-tailed) & 0.004 & 0.008 & 0.011 & 0.007 \\
\cline { 2 - 6 } & N & 38 & 38 & 38 & 38 \\
\hline
\end{tabular}

** Correlation is significant at the 0.01 level (2-tailed), *Correlation is significant at the 0.05 level $(2$-tailed), a. Gender $=$ Female

In addition, to determine the strength of the correlation, it is also possible to see the value of $p$ compared to the level of significance used in this study. The p-value between the actual height and the estimated maximum height (right) and the maximum height (left) is $0.001(<0.05)$, which means that there is a significant correlation between the actual height and the estimated maximum height of the right side and left side respectively. Similarly, between the actual height and estimated minimum height (right), a significant correlation was obtained with a p-value of 0.002 $(<0.05)$, and between the actual height and an estimated minimum height (left) obtained a significant correlation with a p-value of $0,000(<0,05)$. Based on the results of the Pearson correlation coefficient, marked by $(* *)$ on all estimated variables of maximum height and minimum height both right and left side with the information below the table which states that there is a significant positive correlation with actual height at a significance level of $1 \%$ or 0.01 (2-tailed). Although the significance level used in this study is the 0.05 , it does not mean the results of this test indicate that it does not correlate at the 0.05 if the 0.01 is significantly correlated, then, of course, the 0.05 level will also be significantly correlated.

Table 5 Correlation test results of actual height to estimated height with a Carrea's Index (Pearson correlation coefficient) on male subjects.

\begin{tabular}{|c|l|c|c|c|c|}
\hline \multicolumn{2}{|c|}{ Correlations $^{\text {b }}$} \\
\hline \multirow{3}{*}{ Body Height } & $\begin{array}{c}\text { Maximum Body } \\
\text { Height (Right) }\end{array}$ & $\begin{array}{c}\text { Minimum Body } \\
\text { Height (Left) }\end{array}$ & $\begin{array}{c}\text { Maximum Body } \\
\text { Height (Right) }\end{array}$ & $\begin{array}{c}\text { Minimum Body } \\
\text { Height (Left) }\end{array}$ \\
\cline { 2 - 7 } & Pearson correlation & $0.771^{* *}$ & $0.862^{* *}$ & 0.556 & 0.667 \\
\cline { 2 - 7 } & Sig. (2-tailed) & 0.025 & 0.008 & 0.152 & 0.071 \\
\cline { 2 - 7 } & $\mathrm{N}$ & 8 & 8 & 8 & 8 \\
\hline
\end{tabular}

** Correlation is significant at the 0.01 level (2-tailed), * Correlation is significant at the 0.05 level $(2$-tailed), b. Gender $=$ Female 
Table 4 and table 5 above show the results of correlation test for each sex, and there are slight differences in the strength and significance of the correlation. In female subjects (table 4), there were three significant correlation results at the 0.01 level of significance $(* *)$, namely the maximum height of right side variable with a Pearson correlation coefficient of 0.455 ( $\mathrm{p}$ value $=0.004)$; maximum height of left side with Pearson correlation coefficient 0.425 ( $\mathrm{p}$ value $=$ 0.008); and the minimum height of left side with the Pearson correlation coefficient of $0.430(p=0.007)$. While there is one variable with significance at the 0.05 $\left.{ }^{*}\right)$ significance level, namely the minimum height of right side with a Pearson correlation coefficient of 0.409 $(\mathrm{p}=0.011)$. So from the four variables, the maximum height of right side variable is the one with the strongest correlation.

In table 5 , it shows that in male subjects there is one variable that correlates at the $0.01\left(^{* *}\right)$ significance level, that is, the maximum height of left side variable with a Pearson correlation coefficient of $0.862(\mathrm{p}$ value $=$ 0.006 ). In the table, there is one variable that correlates at the $0.05\left(^{*}\right)$ significance level is the maximum height of right side variable with a Pearson correlation coefficient of $0.771(p=0.025)$. From the two variables, although both have coefficient numbers that are very close to 1 and show that they have a very strong correlation, the level of significance of the two is different, it can be seen in the results of each $p$ value, so that from these two variables the strongest correlation is found in maximum height of left side. The other two variables also have a correlation coefficient number that is larger and closer to 1 when compared to female subjects, namely the minimum height of right side variable of $(0.556)$, and the minimum height variable of left side (0.667), which means there is a strong correlation between these variables on actual height, but the correlation between these two variables is not significant at the level of significance used in this study. This is because both of these variables produce a value of $p>0.05$, namely the value of $p=0.152$ for the minimum height of right side variable and the value of $p=0.071$ for the minimum height of left side variable.

\section{Discussion}

In this study, from 46 research subjects with 92 right and left mandibular quadrant samples, the mean of estimated minimum height was lower than the mean of the actual height, and so was the mean of estimated maximum height was higher than the mean of actual height. The mean of actual height (female and male) is $158.95 \pm 8.08 \mathrm{~cm}$, the difference is $0.49 \pm 3.08 \mathrm{~cm}$ from the total estimated height from the right side $(159.44 \pm$ $11.16 \mathrm{~cm})$, and a difference of $0.29 \pm 2.92 \mathrm{~cm}$ from the total estimated height from the left side $(158.66 \pm 11.00$ $\mathrm{cm})$, so this means that the mean of overall height is actually within the range of the mean of total estimated body height (minimum height - maximum height) obtained from the Carrea's Index calculation.

In this study, based on the results of height measurements, it was found that the mean value of the male subject's height had a higher value than the female subject. It was also found when calculating the estimated height from the dimensions of the teeth, and it was found that the mean of male subject's height had a higher value than female subjects, thus indicating that in subjects who were taller, the dimensions of the teeth were also greater. This discovery shows that the dimensions of the teeth are directly proportional to height. Therefore, the dimensions of the teeth are considered to be a measurement tool for estimating height.

A comparison of the successful prediction results in female and male subjects and in both quadrants as a whole in this study had the same percentage of success. However, in each gender, the percentage of success was different for each side of the jaw quadrant, although both were without statistically significant differences (right p-value (0.186); left p-value (0.713)). This difference can be caused by the results of the estimated height for each gender for each side of the jaw quadrant, where the female subjects, have higher body height estimates in right quadrant than the left quadrant, in contrast, in the male subjects, estimated body height in left quadrant is higher than the right quadrant, so this causes the range to be wider and had a higher chances of the actual height being within the estimated range.

In this study, between the genders, there are differences in the percentage of success on the right and left sides, but in previous studies ${ }^{9,10,16}$ found that the percentage of success in the male subject is greater than women on both sides, with no statistically significant difference. This could be due to the small number of male subjects in this study, so further study on a larger sample and a balanced proportion of gender are needed. Similar to what was found in the study of Silva et al. (2014) where the number of female subjects was higher than that of male subjects, and the success percentage of female subjects was higher than male subjects. 
In this study, a similar percentage of successes on the right and left sides and no statistically significant differences were found in each sex on each side of the jaw quadrant indicating that the Carrea's Index method can be used on both women and men on all sides of the jaw quadrant, without affecting the percentage of success. Comparison with previous studies, namely, in a study by Lima et al. (2011), with normal dental structure, the results was higher percentage of success on the right side, as well as in research by Sruthi (2016), while in research by Silva et al. (2014), with normal dental structure, the percentage of success was higher on the left side, as was the study by Rekhi et al. (2014). This can be caused by differences in population and race that are used as research subjects. Although there is a difference in the percentage of success on each side of the jaw of previous studies, there is no statistically significant difference overall, so it can be concluded that the Carrea's Index method can be used on any side of the jaw, of course with normal dental structure conditions as examined in this study.

From the results of the correlation test between actual height and estimated height (maximum height and minimum height) obtained from the Carrea's Index using the Pearson Correlation Coefficient test, there is a positive correlation. The $\mathrm{p}$ value between the actual height and the estimated maximum height (right) and the maximum height (left) is $0.001 \quad(<0.05)$, which means that there is a significant correlation between the actual height and the estimated maximum height of right and left side respectively. Similarly, between the actual height and estimated minimum height (right), a significant correlation was obtained with a $\mathrm{p}$ value of $0.002(<0.05)$, and between the actual height and an estimated minimum height (left) obtained a significant correlation with a $\mathrm{p}$ value of $0,000(<0,05)$. The results of this positive correlation indicate that there is a significant relationship between actual height and height estimation results obtained from measurements of tooth dimensions, namely the arch and chord. If the height of the subject is higher, the estimated height will also become higher, which represents that there will be a larger tooth dimension. In theory, the relationship between height and teeth can be seen from the similarity of the embryological process or its formation ${ }^{10}$. The layer of dentin in a tooth that forms the majority of teeth and determines the dimensions of the tooth, originating from layers of ectomesenchymes (neural crest cells) and long bones, which are most commonly used in measuring height, originating from the mesodermal, these two layers of tissue are basically mesenchymal tissue (connective tissue) which have the same structural component, namely the organic matrix formed from collagen and the inorganic matrix of hydroxyapatite crystals $^{18}$. Therefore, the dimensions of the tooth are considered to be alternative to long bones, especially in forensic cases where no long bones or other body parts are found.

Based on the results of the Pearson correlation test for each gender, there are strong Pearson correlation coefficient numbers in both female and male subjects. But from each correlation coefficient in each gender, there are differences in the level of significance. If on the female subjects, the correlation of actual height to the estimated height is a strong correlation at the 0.01 (with $\mathrm{p}$ value $<0.01$ on the maximum height (left-right), and the minimum height (left)) and $0,05(\mathrm{p}<0.05$ in the minimum height (right)), whereas in male subjects, there was only a strong correlation according to the significance level of 0.01 ( $p<0.01$ in the maximum height (left)) and 0.05 $(p<0.05$ in maximum height(right)). In the estimation results of the minimum height (left \& right), although it shows a strong Pearson correlation coefficient, there is no significant correlation at the the significance level of 0.05 or 0.01 . This can be due to the very small number of male subjects compared to women, so that more male subjects are needed to be able to see the significance at the expected level of significance. As explained in the study by Alwi (2010), that the smaller the significance number, the larger the sample size needed. Conversely the greater the significance number, the smaller the sample size. To get a good significance number, usually a large sample size is needed. Conversely, if the sample size gets smaller, then the possibility of more errors $\operatorname{arises}^{24}$.

Limitation: This study still has some limitations including small sample size and gender imbalance, narrow age range, still limited to normal tooth structure, general and less specific population, and the study caried out on living subjects, therefore further research is needed to address all the limitations of this study.

\section{Conclusion}

The conclusion obtained from this study is that based on the percentage of success of the Carrea's Index method in this study shows that the Carrea's Index method can be used in the Mongoloid population 
in Indonesia to estimate the height of an individual as an aid for individual identification. In addition, there were no statistically significant differences between the gender and the mandibular quadrant side to predict the success of height estimation so that these factors did not correlate or influence the percentage of success in height estimation using the Carrea's Index method.

\section{Conflict of Interest: None}

Source of Funding: Self-Funding

Ethical Clearance: Approved

\section{References}

1. BBC Indonesia. Indonesia negara rawan bencana.

2. Rötzscher K. Forensic and Legal Dentistry. London, New York: Springer; 2014.

3. Budi AT, Juliawati M, Dewanto I, Natsir N, Tanumihardja M. Peran restorasi gigi dalam proses identifikasi korban. PDGI. 2014;63(2):41-45.

4. Senn DR, Souviron RR. Forensic Dentistry. 2nd ed. United State of America: CRC Press, Taylor and Francis Group; 2010. doi:10.1016/03005712(77)90077-X

5. Hossain MZ, Munawar KMM, Rahim ZHA, Bakri MM. Can stature be estimated from tooth crown dimensions? A study in a sample of SouthEast Asians. Arch Oral Biol. 2016;64:85-91. doi:10.1016/j.archoralbio.2016.01.001

6. Bakhtiar HS, Sofyan AM, Muhadar, Soewondo SS. The essence of autopsy in the criminal investigation process. Int J Sci Technol Res. 2019;8(10):9-16. https://www.scopus.com/inward/record.uri?eid=2s2.0-85073801717\& partnerID $=40 \& \mathrm{md} 5=68 \mathrm{f} 58 \mathrm{e} 5$ 2ec0be93b62ed65944221067a.

7. Sukmana BI, Budhy TI, Ardani IG. The potentiation of Mangifera casturi bark extract on interleukin$1 \beta$ and bone morphogenic protein- 2 expressions during bone remodeling after tooth extraction. Dent J (Majalah Kedokt Gigi). 2017;50(1):36. doi:10.20473/j.djmkg.v50.i1.p36-42

8. Nasution MKM, Sitompul D, Harahap M. Modeling reliability measurement of interface on information system: Towards the forensic of rules. In: 10th International Conference on Numerical Analysis in Engineering, NAE 2017. Vol 308. Teknologi Informasi, Fasilkom-TI, Universitas Sumatera Utara, Padang Bulan, Medan, 20155
USU, Indonesia: Institute of Physics Publishing; 2018. doi:10.1088/1757-899X/308/1/012042

9. Lima L, da Costa Y, Tinoco R, Rabello P, Daruge E. Stature estimation by carrea's index and its reliability in different types of dental alignment. J Forensic Odontostomatol. 2011;29(1):7-13.

10. Sruthi R. Carrea's Index and Tooth DimensionsAn Avant-Garde in Stature Estimation: An Observational Study. J Clin Diagnostic Res. 2016. doi:10.7860/JCDR/2016/22646.9046

11. Rahmat RF, Silviani S, Nababan EB, Sitompul OS, Anugrahwaty R, Silmi S. Identification of molar and premolar teeth in dental panoramic radiograph image. In: 2nd International Conference on Informatics and Computing, ICIC 2017. Vol 2018-Janua. Department of Information Technology, Universitas Sumatera Utara, Medan, Indonesia: Institute of Electrical and Electronics Engineers Inc.; 2018:1-6. doi:10.1109/ IAC.2017.8280614

12. Gupta S, Verma Y, Chandra A, Khanna S, Suhail S. A Study on the Reliability of Combined Width of Maxillary Anterior Teeth, Maxillary Canine Width, Head Circumference, Inner Canthal Distance, Inter-Alar Width and Skull Diameter in Sex and Stature Determination. Int J Innov Biol Chem Sci. 2015;6:28-35.

13. Khangura RK, Sircar K, Grewal DS. Four odontometric parameters as a forensic tool in stature estimation. J Forensic Dent Sci. 2015;7(2):132136. doi:10.4103/0975-1475.146367

14. Eboh DEO. Determination of stature from combined maxillary anterior teeth and head dimensions among the Efik and Ibibio of South-South Nigeria. Ann Bioanthropology. 2016;4(1):53. doi:10.4103/23157992.190459

15. Yadav AB. An Odontometric Approach for Estimation of Stature in Indians: Cross- Sectional Analysis. J Clin Diagnostic Res. 2016;10(3):24-26. doi:10.7860/JCDR/2016/18406.7386

16. Rekhi A, Marya CM, Nagpal R, Oberoi SS. Estimation of Stature in a Young Adult Indian Population Using the Carrea's Index. J Forensic Odontostomatol. 2014;30(1):15-23.

17. Silva MA, Sakaguti N, Fernandes M, Mazzilli LE, Silva R, Oliveira R. Carrea`s Method Application to Estimate Stature in Individuals Using Teeth 
Measures in Brazilian Population. J Res Dent. 2014;2(4):298-306.

18. Prabhu S, Acharya AB, Muddapur M V. Are teeth useful in estimating stature? J Forensic Leg Med. 2013;20(5):460-464. doi:10.1016/j. jflm.2013.02.004

19. Ramanna C, Kamath V, Sharada C, Srikanth $\mathrm{N}$. Determination of physical height from crown dimensions of deciduous tooth: A dental morphometric study. J Indian Soc Pedod Prev Dent. 2016;34(3):262. doi:10.4103/0970-4388.186743

20. Jani Y, Parikh S, Dudhia B, Bhatia P, Patel P, Patel R. Body Height from Tooth Size : A Novel Study on Stature Estimation by Odontometric Parameters. J Indian Acad Oral Med Radiol. 2018;30(3):275280. doi:10.4103/jiaomr.jiaomr
21. Yunus M, Achmad MH, Wulansari DP, Haeruddin R. Characteristics vertical position of mental foramen reviewed by panoramic radiography as a guide in predicting individual's age on forensic odontology examination. Pesqui Bras Odontopediatria Clin Integr. 2018;18(1). doi:10.4034/PBOCI.2018.181.63

22. Marjianto A, Sylvia M, Wahluyo S. Permanent tooth eruption based on chronological age and gender in 6-12-year old children on Madura. 2019;100(32):100-104. doi:10.20473/j.djmkg.v52. i2.p100

23. Wattimena J. Kelainan Gigi akibat Gangguan Pertumbuhan dan Perkembangan. 2017:1-24.

24. Alwi I. Kriteria empirik dalam menentukan ukuran sampel pada pengujian hipotesis statistika dan analisis butir. J Form. 2010;2(2):140-148. 